\title{
UN LIBELO ANTIJUDÍO EN LA LITERATURA POPULAR IMPRESA DEL SIGLO XVI
}

\author{
MARÍA SÁNCHEZ PÉREZ \\ CCHS (CSIC)
}

\section{RESUMEN}

En este artículo se edita y estudia un libelo antijudío conservado en un pliego suelto poético del siglo XVI y atribuido al ciego coplero Francisco González de Figueroa. Gracias a un rastreo de diversas fuentes medievales y coetáneas, hispánicas y extranjeras, relacionadas con las acusaciones de crímenes rituales contra los judíos, hemos comprobado que esta narración es un eslabón más de una larga cadena de libelos de sangre antijudíos surgidos en Europa, que tuvieron una amplia y dilatada difusión durante varios siglos.

Palabras clave: Francisco González de Figueroa, pliegos sueltos, literatura popular, Geoffrey Chaucer, Cuentos de Canterbury, libelo de sangre, acusación de crimen ritual, antijudaísmo.

\section{AN ANTI-JEWISH LIBEL IN THE PRINTED POPULAR LITERATURE OF THE 16th CENTURY}

\begin{abstract}
In this article there is edited and studied an anti-Jewish blood libel preserved in a Spanish poetic chapbook («pliego suelto») of the $16^{\text {th }}$ century and attributed to the blind traditional poet («ciego coplero») Francisco González de Figueroa. Thanks to a tracking of diverse medieval and contemporary sources, Hispanic and foreign, related to the accusations of ritual murder against Jews, we have verified that this narration is a more link of a long chain of anti-Jewish blood libels arisen in Europe, which had a wide and extensive diffusion for several centuries.
\end{abstract}

Key words: Francisco González de Figueroa, Spanish chapbooks (pliegos sueltos), popular literature, Geoffrey Chaucer, The Canterbury Tales, blood libel, accusation of ritual murder, antiJudaism.

A consecuencia del decreto de expulsión de los judíos de las coronas de Castilla y Aragón -firmado por los Reyes Católicos el 31 de marzo de 1492 - muchos de ellos se exiliaron, aunque otros decidieron convertirse y bautizarse; entre los exiliados, algunos optaron por trasladarse al vecino reino de Portugal. Sin embargo, solamente cinco años después, el monarca luso les obligó a abandonar el país o convertirse al catolicismo, bajo pena de muerte 
y confiscación de sus bienes ${ }^{1}$. No obstante, el rey Manuel I de Portugal al ver cómo miles y miles de judíos preferían el destierro y temiendo las consecuencias —especialmente las pérdidas económicas_-, decretó prohibir la salida del país, obligando así a todos los judíos a convertirse. Éstos pasaron a ser de este modo - como ocurría en España— cristianos nuevos, aunque muchos de ellos seguirían practicando el judaísmo en secreto. La Inquisición, instaurada en España en 1478 y, posteriormente, en Portugal en 1536, siempre estuvo atenta en la búsqueda de estos criptojudíos y, sin duda, tanto los monarcas como el Santo Oficio llevaron a cabo una durísima represión contra ellos en toda la Península durante la Edad Moderna.

De esto modo, la hostilidad — que, con altibajos venía acrecentándose desde los saqueos y persecuciones de 1391 - no cesó y el sentimiento antijudío permaneció vigente en la mentalidad colectiva durante los siglos XVI y XVII, e incluso tiempo después. El antijudaísmo religioso ${ }^{2}$ - fundamentalmente- es evidente durante los siglos posteriores a la expulsión y aparecen numerosas muestras y referencias en las letras hispánicas. Sin duda, las más conocidas son las que nos han llegado a través de la literatura «mayor», pero también en la popular encontramos ejemplos de antijudaísmo ${ }^{3}$. Quizá la obra más conocida y difundida en pliegos sueltos poéticos sea la de Juan de Agüero o de Trasmiera, conocida como las Coplas del perro de Alba, de la que se han conservado varias ediciones en el siglo XVI e incluso en el XVII. El texto narra el pleito interpuesto por los judíos de Alba de Tormes contra un perro en dicha localidad salmanti-

${ }^{1}$ En gran medida, este hecho se debió a la boda entre Manuel I e Isabel, hija de los Reyes Católicos: «La violencia del rey contra sus súbditos no deja de estar íntimamente relacionada con sus intereses políticos frente a su vecina España [...] los monarcas españoles ya se habían dado cuenta de su error al expulsar a los judíos, de modo que lo único que podían hacer era tratar de contrarrestar las ventajas que de aquel hecho podían derivarse para Portugal. Por tanto, impusieron como condición del matrimonio entre la princesa Isabel y el rey portugués la expulsión de todos los infieles. Por amor de Isabel, pero —más verosímilmente- por razones de Estado, don Manuel aceptó la condición de los Reyes Católicos», NOVINSKY, Anita. «Judíos y cristianos nuevos de Portugal». En MÉCHOULAN, Henry (ed.). Los judíos de España. Historia de una diáspora (1492-1992). Madrid: Trotta, 1993, pp. 91-121; concretamente la cita está tomada de las pp. 96-97.

${ }^{2}$ Una síntesis de las diferentes variedades de antijudaísmo en DÍAZ-MAS, Paloma; DE LA PUENTE, Cristina. Judaísmo e Islam. Barcelona: Crítica, 2007, especialmente las pp. 367-369. Un estudio clásico sobre el tema es el de Léon Poliakov sobre la historia del antisemitismo, en varios volúmenes. Especialmente para la época que nos ocupa, consúltese POLIAKOV, Léon. Historia del antisemitismo: de Mahoma a los marranos. Barcelona: Muchnik Editores, 1986. Para el caso español, véase el estudio de ÁLVAREZ CHILLIDA, Gonzalo. El Antisemitismo en España. Madrid: Marcial Pons, 2002, especialmente, para los siglos XVI y XVII, las pp. 29-92.

${ }^{3}$ Véanse, por ejemplo, HERMOSILLA ÁLVAREZ, M. ${ }^{a}$ Ángeles. «Referencias antisemíticas en la literatura popular del Siglo de Oro». En Actas de las Jornadas de Estudios Sefardíes. Cáceres: Universidad, 1981, pp. 161-168; PEDROSA, José Manuel. «Los judíos en la literatura tradicional española». En Hassán, Iacob M.; Izquierdo Benito, Ricardo (coords.). Judíos en la literatura española. Cuenca: Universidad de Castilla La Mancha, 2000, pp. 403-436. 
na. Se trata de una burla, una sátira, o mejor, de «una broma despiadada contra los judíos en Alba de Tormes» ${ }^{4}$. Carlos Carrete indicaba que, al leer la obra, se puede advertir cómo «al autor le falta ingenio y le sobra hostilidad hacia los judíos» ${ }^{5}$. Los especialistas indican que, probablemente, la fecha de composición debió de ser anterior a la expulsión y «la edición más temprana de la que conservamos mención segura es de 1527 , pues aunque no conservada, tenemos el testimonio fiable de su compra en el Regestrum colombino» ${ }^{6}$. La obra está plagada de imágenes estereotipadas y hostiles contra los judíos.

Queremos fijar nuestra atención ahora en otro ejemplo de antijudaísmo recogido en la literatura popular impresa ${ }^{7}$. Se trata de un pliego suelto poético del siglo XVI que contiene una composición antijudía, cuya acción se sitúa en la década de los setenta. La obra fue compuesta, según consta en el título, por Francisco de Figueroa ${ }^{8}$. Como acertadamente señaló María Cruz García de Enterría, la obra de este coplero debe asimilarse con la de Francisco González de Figueroa, de quien conservamos varios pliegos más ${ }^{9}$. Sin duda, debió ocurrir lo siguiente: «al imprimirse [...] en Portugal, los tipógrafos portugueses siguieron la costumbre de su tierra, de tomar por principal apellido el que va colocado en segundo lugar» ${ }^{10}$. Poco es lo que sabemos de este autor:

Francisco González de Figueroa, resulta personaje tan enigmático y oscuro como Diego López. Otra vez los títulos de sus pliegos serán la única fuente disponible, que sepamos, sobre su biografía. Fue natural de Murcia y según expresión gentil del impresor, "privado del sentido visivo" ${ }^{11}$.

${ }^{4}$ GARCÍA DE ENTERRÍA, Ma . Cruz. Pliegos poéticos españoles de la Biblioteca Universitaria de Cracovia. Madrid: Joyas Bibliográficas, 1975, p. 55.

${ }^{5}$ CARRETE PARRONDO, Carlos. Fontes Iudaeorum Regni Castellae. I. Provincia de Salamanca. Salamanca: Universidad Pontificia de Salamanca, 1981, pp. 35-41, concretamente la cita está tomada de la última página.

${ }^{6}$ FERNÁNDEZ VALLADARES, Mercedes; INFANTES, Víctor. Pliegos cántabros del siglo XVI (poesía). Santander: Cuévano, 1985, p. 8.

${ }^{7}$ Este trabajo es producto de mi contrato Juan de la Cierva en el Consejo Superior de Investigaciones Científicas (CSIC), dentro del proyecto de investigación «Los sefardíes ante sí mismos y en sus relaciones con España» II, (FFI2009-07026), del Ministerio de Educación y Ciencia.

${ }^{8}$ Se trata de la primera composición del pliego que figura en la entrada 194 de la obra de RODRÍGUEZ MOÑINO, Antonio. Nuevo Diccionario Bibliográfico de Pliegos Sueltos Poéticos. Siglo XVI. Askins \& Víctor Infantes, Arthur L.-F. (ed. corregida y actualizada). Madrid: Castalia \& Editora Regional de Extremadura, 1997 (en adelante nos referiremos a él utilizando solamente sus dos primeras palabras, Nuevo Diccionario).

${ }^{9}$ Solamente con echar un vistazo a los títulos de las piezas que de este autor se han conservado se deduce que la temática religiosa - tratados espirituales, milagros, martiriosestá presente en buena parte de sus obras. Véanse, por ejemplo, los números 229, 232 y 233 del Nuevo Diccionario.

${ }^{10}$ GARCÍA DE ENTERRÍA, Ma . Cruz. Pliegos poéticos españoles en Bibliotecas de Portugal. Madrid: Joyas Bibliográficas, 1982, p. 27.

${ }^{11}$ ASKINS, Arthur L.-F. Pliegos poéticos del siglo XVI de la Biblioteca RodríguezMoñino. Madrid: Joyas Bibliográficas, 1981, pp. 18-19. 
El tono de la composición que ahora nos ocupa no difiere del resto de relaciones de sucesos milagrosos de la época ni de las obras que se nos han conservado de este ciego coplero. Aunque el pliego que nos interesa carece de fecha y lugar de impresión concreto, García de Enterría indica que:

Es pliego con texto castellano, pero impreso en Lisboa, según podemos deducir de dos datos: a) la Licencia «do supremo conselho da santa Geral Inquisição», escrita en portugués y fechada en 22 de septiembre de 1578 ; b) la abundancia de lusismos en el título que, por este rasgo, puede creerse redactado en Lisboa al imprimir este pliego sobre una edición española ${ }^{12}$.

Como esta autora señala, no fueron infrecuentes en la época los casos en que un pliego salía de prensas españolas y se reeditaba en Portugal. En el caso concreto de la composición antijudía, este hecho vendría a demostrar el interés que el tema suscitaba en toda la Península Ibérica.

Tras la licencia de los inquisidores lusos y de tres pequeños grabados xilográficos, el pliego comienza con el siguiente título:

Aquí se contienen dos notables y graciosos romances sobre dos maravilhosos milagros que sucedieron em este año de 1576. El primero em la ciudad de Aviñón, en Francia, com hum hijo de una biuda y un judío. Y el segundo em Alemaña la Alta, so un sacerdote que desseava ver a Jesucristo en forma de niño y assí permitió nuestro Señor mostrársele un día diziendo missa. Com dos glosas o dos vilancicos. Compuestos por Francisco de Figueroa, privado de la vista, vezino de Murcia.

Las dos primeras composiciones son relaciones milagrosas: la que abre el pliego, de tono antijudío; y, la segunda finaliza con una exhortación a los herejes, especialmente destinada a los luteranos, para que abracen la fe verdadera: el catolicismo. Las dos composiciones que cierran el pliego continúan con el tono religioso de toda la obra, de este modo, tenemos una «Glosa a un villancico contrahecho, a un que dezía 'Derramaste el agua, la niña'» y un villancico final que comienza «Dios combida al hombre | y Él es el manjar, | pues qué ay más que dar». Se observa, por tanto, cómo Francisco González de Figueroa «trata el tema religioso según su peculiar estilo, ya metido de lleno en la más tópica 'literatura de cordel'»13. Queremos prestar atención en este estudio a la composición que abre el pliego y que presentamos a continuación para seguir después con su análisis ${ }^{14}$ :

${ }^{12}$ GARCÍA DE ENTERríA, Mª Cruz. Pliegos... de Portugal, op. cit., p. 27.

${ }^{13}$ Idem, pp. 27-28.

${ }^{14}$ Para la edición, seguimos las normas del Proyecto de investigación «Cultura popular y cultura impresa: corpus, edición y estudio de la literatura de cordel de los siglos XVI y XVII» [BFF 2003-00011]. Guía para los miembros del equipo y colaboradores, Salamanca: SEMYR, 2003, pp. 8-9. 
Por las partes universas de todo el orbe criado se relate, cuente y diga este caso memorado

5 que subcedió en Avinñón, pueblo en Francia nombrado, donde Dios ordenó y quiso tal milagro aver obrado, para que sus maravillas

10 siempre se ayan publicado, porque el moro y el judío confunda su ley y estado y entandan qué cosa es fee y la ley que Dios ha dado,

15 sancta ivangelizada, y que Jesús la ha ordenado para nuestra salvación, pues por nos, su vida ha dado. Dexemos aparte aquesto,

20 pues está bien declarado, y relátese el subcesso harriba significado para que el sabio y curioso y todo lo que ay criado

25 vea quanto vale y pode la madre de Dios sagrado, pues que por su intercessión fue esto que he dicho obrado con un hijo de una biuda,

30 de niño bien doctrinado, criado em sanctas custumbres y a todas virtudes dado, y más que a nuestra Señora era muy afficionado

35 y siéndole tan devoto, em un conto concertado cantava muy muchas vezes una antíphona y tratado em loor de la sancta Virgem,

40 que tenemos ya explicado, Alma redemptoris mater era el cantar señalado, que em romance significa, para ser mejor notado,

45 «Alma y madre de Jesús, redemptor y hombre tornado». Y como aquesto cantaba el pueblo estava espantado y assí un canónigo bueno,

50 que lo oyó muy admirado, llevó a su casa este niño, donde fue muy regalado para que allí le cantasse aquel cántico loado.

55 Mas un perverso judío, de oíllo muy enojado, buscava mañas y modos cómo aquel niño preciado no biviesse en este mundo

60 por ser bien intencionado, ándavale persiguiendo por cogello en despoblado, por cumplir su mal intento y desseo endemoniado.

65 Em este tiempo que cuento la fiesta se uvo llegado del sagrado nascimiento de la Virgem sin peccado y haziéndose esta fiesta

70 en un lugar apartado el niño pidió licencia a aquel canónigo honrado, para ir do celebravan la fiesta que hemos nombrado

75 y alcançada la licencia fue el niño regozijado, pero saliole al camino el judío apassionado que allí su casa tenía

80 do fue nascido y criado y dixo: - ¿Dónde vas, niño, de las gentes tam amado? Respondiole: -A ver la fiesta que la iglesia ha publicado

85 del nascimiento glorioso de la que Dios ha engendrado. Rogole luego el judío, con rostro dissimulado, que cante aquella canción

90 que contino ha acostumbrado. Començó el bendicto niño aquel verso memorado y en començando el judío sacó un cuchillo afilado

95 y por medio la garganta al niño se lo ha hincado, donde luego cayó muerto el niño glorificado. [El] judío que esto vio

100 a su casa lo ha llevado [a] hazer un hoyo muy presto donde al niño ha sepultado. 
Y passada ya la fiesta la madre con gran cuidado

105 que de su hijo tenía, como tanto se ha tardado, cas del canónigo fue a saber si era llegado. El canónigo afflegido

110 dixo que estava espantado y que no es buena señal por allá averse quedado; mas la madre que lo amava, su coraçón trespassado,

115 tomó de presto el camino por do el niño ha caminado y al salir de la ciudad em cas del judío ha entrado, por su hijo le pregunta

120 si lo ha visto o encontrado. Respondió presto el judío que tal niño no ha hallado, pero por gracia de Dios muerto el niño y enterrado,

125 cantava baxo la tierra con canto muy concertado, cantava el verso divino em su niñez tan usado. La madre quando lo oyó

130 media muerta se ha quedado, mas despois de buelta en sí, al judío le ha rogado que muestre do está su hijo o do lo tiene enterrado.

135 El judío se lo niega, con fiero l-amenazado, pero la buena muger a la ciudad se a tornado y al canónigo dio cuenta

140 de todo lo que ha passado y cómo en casa del judío después de aver allá entrado oyó cantar a su hijo, mas en dónde no a atinado.

145 Luego el canónigo junta gente y bien acompañado se fue a casa del judío y aun no avía bien llegado quando oyó la melodía

150 del niño martirizado y apremiando aquel judío el lugar luego ha mostrado y cavando brevemente el niño bivo han sacado,

155 por medio de la garganta el cuchillo atravessado.

Y lleváronlo a la iglesia y al cabildo congregado dio velación desto hecho

160 contando cómo ha passado y sacándole el cuchillo su ánima a Dios ha dado, do sintieron gran olor sobre aquel cuerpo finado.

165 Y el judío viendo aquesto el baptismo ha demandado y gran parte de sus bienes a la biuda los ha dado. Noten todos los christianos 170 milagro tam sublimado, digno de veneración y ser siempre celebrado. Saluda siempre a María, pues que tanto ha trabajado

175 por nosotros y no cessa delante su hijo amado de presentar nuestras preces, teniendo de nos ciudado. Roguemos que nos alcance 180 en este mundo angustiado la gracia con que alcancemos el reino beatificado.

Nos hallamos ante una relación de sucesos compuesta en romance, es decir, en la forma poética narrativa por excelencia, ya que, como años después señalará Lope de Vega en su Arte nuevo de hacer comedias: «las relaciones piden los romances, | aunque en octavas lucen por extremo». Se trata, como puede verse, de un romance con rima consonante en -ado, lo que delata que estamos ante una composición poco tradicionalizada, ya que, con frecuencia, la rima consonante es más habitual en las composiciones literarias de autor, mientras que los poemas tradicionales tienden a la rima asonante. 
Como se observa en el texto, el antijudaísmo domina toda la composición, aunque en este caso el judío se convierte al cristianismo y no se acaba con su vida, como ocurre en otras tantas obras literarias castellanas, aunque sobre este aspecto volveremos más adelante ${ }^{15}$. Sin duda, ya desde la Edad Media, hay numerosos antecedentes antijudíos en la literatura hispánica ${ }^{16} \mathrm{y}$, al mismo tiempo, existen varios elementos tradicionales y folklóricos que aparecen y se conjugan en la narración, junto con los rasgos y las características propias de las relaciones de sucesos de finales del Quinientos. Así, por ejemplo, no es infrecuente que la acción se sitúe más allá de nuestras fronteras, en este caso, en la ciudad de Aviñón ${ }^{17}$, aunque quizá este dato apunte a la posible fuente de donde tomó esta narración Francisco González de Figueroa, pero a ello nos referiremos posteriormente. Piénsese, no obstante, que los judíos fueron expulsados de Francia en 1394 y que, legalmente, sólo pudieron emigrar a territorio francés los conversos, cuya presencia era tolerada, ya

${ }^{15}$ Recuérdese, por poner un ejemplo, el conocido milagro XVI que recoge Gonzalo de Berceo en sus Milagros de Nuestra Señora, donde el padre judío, al ver que su hijo ha comulgado decide quemarlo vivo en el horno. Se produce entonces el milagro, ya que el niño no sufrirá, gracias a la intervención de la Virgen, ningún castigo, sino que será finalmente el padre quien muera consumido en el horno. Véase, por ejemplo, en GONZALO DE BERCEO. Milagros de nuestra Señora. Baños, Fernando (ed.). Barcelona: Crítica, 1997, pp. 87-92.

16 Véanse, entre otros, ARBÓS AYUSO, Cristina. «Los judíos en la literatura medieval española (siglos XIII-XIV): los judíos y la economía; protecciones y privilegios». En Actas de las Jornadas de Estudios Sefardies, op. cit., pp. 141-150; FERNÁNDEZ VALLADARES, Mercedes; Víctor INFANTES, op. cit., especialmente pp. 7-10, 37-44; 73-120; ARBÓS AYUSO, Cristina. «Judíos y conversos: un tema tópico en la poesía medieval». En Ruiz Gómez, Francisco; Espadas Burgos, Manuel (coords.). Encuentros en Sefarad. Actas del Congreso Internacional "Los judios en la historia de España». Ciudad Real: Instituto de Estudios Manchegos, 1987, pp. 137-152; PEDROSA, José Manuel. Las dos sirenas y otros estudios de literatura tradicional. Madrid: Siglo Veintiuno de España, 1995, especialmente el capítulo «El macho de Juan de Mena, el romancillo de El bonetero y su caballo y más caballos enfermos en la tradición folclórica», pp. 3-34; CANSINOS ASSENS, Rafael. Los judíos en la literatura española. Valencia: Fundación ONCE, 2001, especialmente el capítulo dedicado a «La Sara de 'Rosa de la Pasión' (en Leyendas) de Gustavo Adolfo Bécquer», pp. 4955, ya que se refiere a un crimen ritual judío; HASSÁN, Iacob. M.; IZQUIERDO BENITO, Ricardo (coords.). Judios en la literatura española, op. cit.; CONDE, Juan Carlos;Víctor INFANTES. De cancioneros manuscritos y poesía impresa. Estudios bibliográficos y literarios sobre lírica castellana del siglo XV. Madrid: Arco-Libros, 2007, en concreto el capítulo 7 «Antes de partir. Un poema taurino antijudaico en el Toledo medieval ( 1489 ?)», pp. 87-104; DÍAZ-MAS, Paloma. «La visión del otro en la literatura oral: judíos y musulmanes en el romancero hispánico». Studi Ispanici, 2007, 32, pp. 9-36. Véase, además, como visión de conjunto DÍAZ-MAS, Paloma. «Huellas judías en la literatura española». Luces y sombras de la Judería Europea (siglos XI-XVII). Pamplona: Gobierno de Navarra, 1994, pp. 87-118.

${ }^{17}$ Es bastante extensa la bibliografía en torno a los judíos en Francia. No obstante, en el caso concreto de Aviñón, puede consultarse, MOSSÉ, Armand. Histoire des juifs d'Avignon et du Comtat Venaissin. Paris: Librairie Lipschutz, 1934. 
que la existencia de comunidades judías no estaba autorizada. Por lo tanto, únicamente se aceptó a cristianos nuevos, aunque no podemos afirmar si éstos siguieron judaizando o no. También es cierto que, durante la diáspora, muchos judíos pasaron por Aviñón para asentarse, posteriormente, en otros territorios. Sin embargo, no sabemos si el ciego coplero que compone la narración conocía todos estos datos históricos. Con todo, es poco probable que los oyentes y lectores a los que dirigía su composición supieran de la situación concreta de los judíos en Aviñón, de este modo - como ocurre tantas veces cuando nos las habemos con esta literatura de cordel-, lo que interesa es la noticia en sí, el milagro y la moraleja final que se desprende del texto.

Como puede observarse al leer la narración, el milagro y la conversión están vinculados a ese niño que - como ocurre en muchas de estas relaciones de sucesos - era «bien doctrinado, | criado em sanctas custumbres | y a todas virtudes dado» (vv. 30-32) y que, además, entonaba de continuo el conocido cántico mariano Alma redemptoris mater ${ }^{18}$. El judío, al no aceptar a Jesús como el Mesías, tampoco venera la figura de María y, por ello, consideraría idolatría que el niño fuese entonando esos cantos litúrgicos delante de su casa. No obstante, no era frecuente que estas zonas estuviesen extramuros, como sí indica el texto ${ }^{19}$.

En la narración, por tanto, encontramos la unión de dos tradiciones ampliamente difundidas en los Siglos de Oro: por una parte, las relaciones de sucesos milagrosos obrados por intercesión de la Virgen —en sus diversas advocaciones - y, por otro, los libelos de sangre contra los judíos, a los que nos referiremos posteriormente.

En efecto, solamente si tenemos en cuenta las narraciones de milagros en pliegos sueltos poéticos del Quinientos, el número es bastante elevado. Por citar solamente algunos ejemplos, el primero conservado del que tenemos noticia apareció impreso en 1562 y lleva por título: Aquí se contienen dos maravillosíssimos y dulcíssimos milagros de la sereníssima, sin par nacida, Madre de Dios y Señora Nuestra, acaecidos a devotos suyos, los quales tenían cuenta con rezar su rosario cada día, compuesto por Gaspar de la Cintera, «privado de la vista» y «vezino de Granada». El género, sin duda va afianzándose a medida que avanza la centuria, de ahí que otro de los cople-

18 «Palabras iniciales de una de las cuatro Antífonas cantadas en las Completas y las Laudes, en honor a la Santísima Virgen, en varias estaciones del año» y más adelante se añade «La Antífona debió haber sido muy popular en Inglaterra antes y después de su tratamiento por Chaucer en El cuento de la priora». En Enciclopedia Católica, s. v. alma redemptoris mater, en la siguiente dirección en línea:

$<$ http://www.enciclopediacatolica.com/a/almaReMa.htm> [consultada el 15 de febrero de 2009].

${ }^{19}$ Así ocurría, al menos, en la mayor parte de las ciudades de España, ya que «desde muy pronto a los reyes les preocupó la seguridad de los judíos. Por esta razón, solía elegirse para construir su barrio una zona considerada 'segura' dentro de la ciudad». LACAVE, José Luis. Juderías y sinagogas españolas. Madrid: MAPFRE, 1992, p. 12. 
ros bien conocidos, como Diego Gasque, decidiera también componer otra relación de sucesos siguiendo esta misma línea temática: Veríssima y notable relación, la qual trata de dos milagros que la santíssima Virgen de las Virtudes ha hecho con una devota suya en la villa de Zorita, en este año de 1595. $\mathrm{O}$, por último, señalar la Historia de las mercedes tan cumplidas que la Virgen del Monte Carmelo obró con tres hermanas cofradas de la sancta hermandad de la Virgen del Carmelo, do oirán los fieles christianos el discurso de su vida y muerte destas bienaventuradas de Juan de Mesa ${ }^{20}$. Todas ellas pertenecen a una parcela de la literatura religiosa popular y estaban ya bien enraizadas en la mentalidad colectiva desde la Edad Media, pues desde los siglos XII y XIII comenzaron a proliferar las colecciones de milagros marianos. Durante las centurias posteriores van a multiplicarse las apariciones y las acciones milagrosas atribuidas a la Virgen, ya que existe una literatura devocional y una religiosidad popular viva y muy activa durante la Edad Media y los Siglos de Oro.

Es importante señalar que la narración del caso milagroso que ahora nos ocupa contiene algunos motivos folklóricos bien conocidos en la cuentística tradicional desde antiguo. Así, por ejemplo, en la Primera crónica general de España de Alfonso X se recoge «El crucifijo herido por un judío», donde se expresa la crueldad y maldad de los judíos. Como afirma María Jesús Lacarra:

También en las Partidas (VII, XXIV, 2), insiste Alfonso X en que los judíos, «por la traición que fezieron en matar a su Señor», perdieron la honra y sus privilegios. Relatos muy similares se encuentran en los ejemplarios y colecciones de milagros, salvo que al final, asombrado el judío al ver manar la sangre del crucifijo se convierte (Tubach, núm. 1373). Así lo encontramos en el Libro de los exemplos, núm. 90 y núm. 91; motivos análogos retoma Gonzalo de Berceo (Milagros, núm. 18) y Alfonso X (Cantigas, núm. 12) ${ }^{21}$.

Es también de sobra conocido en la literatura popular universal, e hispánica en particular, el motivo folklórico del niño perdido o secuestrado que canta desde su encierro para que lo encuentren. Antti Aarne y Stith Thompson en su Motif-Index of Folk Literature ${ }^{22}$ recogen bajo el tipo 311B* «La bolsa cantante» que, en la tradición peninsular conoce numerosas variantes, así por ejemplo, El zurrón que cantaba, Canta zurrón, etc. Sin duda, fue un cuento folklórico bien conocido durante los Siglos de Oro, pues ya Gonzalo

20 Se trata de las entradas 147, 217 y 362.5 del Nuevo Diccionario. En CARRO CARBAJAL, Eva Belén; SÁNCHEZ PÉREZ, María (ed. y estudio de la última obra). Literatura popular impresa en La Rioja. Cátedra, Pedro M. (dir.). San Millán de la Cogolla: CiLengua, 2008; especialmente pp. 103-112 y 185-197.

${ }^{21}$ LACARRA, María Jesús. Cuento y novela corta en España. I. Edad Media. Barcelona: Crítica, 1999, p. 329.

${ }^{22}$ Motif-Index of Folk-Literature. A Classification of Narrative Elements in Folktales, Ballads, Fables, Mediaeval Romances, Exempla, Fabliaux, Jest-books and Local Legends. Copenhague-Bloomington: Indiana University, 1955-1958, 6 vols. 
Correas lo incluyó en su Vocabulario de refranes y frases proverbiales, donde recogía la siguiente versión: «Canta, zurrón, canta, si no, darte he una puñada ${ }^{23}$. Como sabemos, normalmente era una niña la que se encontraba encerrada en el zurrón y conseguía ser rescatada gracias a que sus familiares reconocían su voz dentro del $\mathrm{saco}^{24}$. De modo semejante ocurre en el cuento de Garbancito, quien, desde el estómago del buey — sobre este aspecto existen también diferentes variantes-, gritaba dónde se encontraba y así pudo ser salvado: «en la tripa del buey que se mueve | donde ni nieva ni llueve» - o «sóc a la panxa del bou | on no hi neva ni plou», si nos referimos al Patufet catalán-. De este modo, como ocurre en esta composición de Francisco González de Figueroa, el niño asesinado por el judío puede ser rescatado gracias a que, incluso enterrado, sigue cantando el himno mariano.

Es importante señalar que también están muy enraizados en la mentalidad europea, fundamentalmente a partir del siglo XII, los libelos de sangre contra los judíos y resultan clave para poder comprender la narración que ahora nos ocupa:

Blood libel, the allegation that Jews murder non-Jews, especially Christian children, in order to obtain blood for the Passover or other rituals: most blood libels occurred close to Passover, being basically a another form of the belief that Jews had been and still were responsible for the passion and crucifixion of Jesus Christ, the divine child; a complex of deliberate lies, trumped-up accusations, and popular beliefs about the murder-lust of the Jews and their bloodthirstiness, based on the conception that Jews hate Christianity and mankind in general ${ }^{25}$.

Como sabemos, estas acusaciones se remontan a la antigüedad, pues ya en el siglo I a. de C. se acusaba a los judíos de practicar sacrificios humanos ${ }^{26}$. No obstante, estos libelos comienzan a difundirse por Europa desde la alta Edad Media, concretamente la primera acusación de crimen ritual conocida en Europa surge en Inglaterra en el siglo XII y a ella nos referiremos más adelante. En todos estos libelos y calumnias de crimen ritual se acusaba a los

${ }^{23}$ Añadía, a continuación la siguiente explicación: «El cuento que fingen es: que un romero traía un gran zurrón, y decía que le hacía cantar, por sacar mucho con la invención; y era que llevaba dentro un muchacho, que cantaba en diciéndole esto.». CORREAS, Gonzalo. Vocabulario de refranes y frases proverbiales (1627). Combet, Louis (ed.); Robert Jammes, Robert; Mir-Andreu, Maïte (rev.). Madrid: Castalia, 2000, p. 153.

${ }^{24}$ Puede leerse el cuento completo en la Revista de Folklore, 21 (1982), pp. 104-108; y también en la siguiente dirección electrónica [en línea]: <http://www.funjdiaz.net/folklore/ 07ficha.cfm?id=187> [consultada el 14 de marzo de 2009].

${ }^{25}$ Encyclopaedia Judaica. Nueva York: Thomson \& Gale, 2007, s. v. blood libel. Al final de la entrada se cita bibliografía sobre este asunto.

${ }^{26}$ FLAVIO JOSEFO en su obra Contra Apión. Sobre la antigüedad del pueblo judio (Libro II, capítulo VIII, 89) refutaba las acusaciones vertidas por Apión, quien sostenía que al entrar Antíoco IV Epífanes en el Templo descubrió a un griego que había sido secuestrado por los judíos y que estaba siendo cebado para, posteriormente, sacrificarlo como víctima ritual. 
judíos de realizar sacrificios humanos para después emplear la sangre en diversos rituales religiosos. Casi todas estas acusaciones suelen coincidir en los aspectos más significativos y, normalmente, la víctima era un niño que era secuestrado o comprado. Posteriormente, era ocultado por la comunidad judía, en alguna casa particular, en la sinagoga, etc. Una vez fijado el día del sacrificio, se seguían, más o menos, las mismas pautas que en la pasión de Jesucristo: los judíos se reunían en el lugar donde se procedería al sacrificio y se escenificaba una especie de juicio donde el niño era sometido a escarnio, burlado y, finalmente, condenado a muerte. Comenzaba después la tortura con latigazos, mutilaciones, etc., posteriormente, se le colocaba al niño una corona de espinas, para acabar siendo crucificado. Terminaba el sacrificio al clavarle algún puñal, lanza, etc., en el corazón. Algunas versiones señalan que la muerte de la víctima era el único fin de los judíos, mientras que en otras se recogía la sangre del niño para poder utilizarla en diferentes rituales.

En las Partidas de Alfonso X (Partida VII, XXIV) donde se refiere a los judíos se indica — no sin cierto escepticismo- que tales crímenes rituales parece que ocurren fuera de nuestras fronteras y que, por lo tanto, si esto llegase a suceder en Castilla, deberían tomarse las medidas represoras que allí se señalan. En España la primera acusación de crimen ritual se sitúa a mediados del siglo XIII y se refiere a la muerte de Dominguito del Val. Según cuenta la leyenda:

en el año 1250, el día 31 de octubre, murió crucificado. Su muerte obedeció a una cruel pragmática de los judíos por la que se liberaba de impuestos, pechas y alcabalas a quien entregase a un niño cristiano para renovar en él la Pasión de Cristo. Con este propósito el judío Albayuceto raptó al niño y, ocultamente, lo entregó para ser crucificado en la aljama. Clavado en una pared con tres clavos, le abrieron su costado con una lanza mientras moría cantando gozos y motetes. Para esconder el homicidio los judíos le cortaron la cabeza y las manos y las arrojaron a un pozo, a la vez que su pequeño cuerpo era sepultado secretamente. El hallazgo y rescate de su cadáver [...] se debió a las señales hechas por una extraña luz que iluminaba el lugar del enterramiento $[\ldots]^{27}$.

Son evidentes las similitudes que existen entre esta leyenda y la narración de Francisco González de Figueroa, especialmente por lo que se refiere al final de la historia, pues el niño pudo ser rescatado gracias a esas «señales» que enviaba y, además, parece que, finalmente, el judío se convirtió al cristianismo del mismo modo que ocurre en el pliego suelto. Nuestro coplero tendría

${ }^{27}$ RINCÓN GARCÍA, Wifredo. Santo Dominguito del Val, mártir aragonés. Ensayo sobre su historia, tradición, culto e iconografía. Zaragoza: Gobierno de Aragón, 2003, pp. 16-17. Dominguito fue canonizado, es considerado el patrón de los monaguillos y en su capilla dentro de la catedral de El Salvador, en Zaragoza, todavía se veneran sus reliquias. La Iglesia celebra su día el 31 de agosto. 
aquí, por lo tanto, material suficiente para recrear su obra, pero vayamos por partes.

El crimen de Santo Dominguito del Val inicia esta tradición en España y otros libelos surgidos en el siglo XV formarían parte, sin duda, del ideario colectivo de la sociedad renacentista:

Durante todo el siglo XV son frecuentes las acusaciones de sacrilegios y crímenes rituales atribuidos a los judíos españoles: Segovia 1406 (robo y ultraje de una hostia consagrada); Toledo 1445 (pólvora en el recorrido de la procesión de Corpus Christi); Tábara, en Zamora, 1460 (abrojos en las calles por donde habían de pasar los cristianos penitentes); Valladolid 1452 (crucifixión de un niño cristiano, que se repite dos años después en un pueblo zamorano del señorío del marqués de Almarza); Sepúlveda 1468 (con iguales características); Puerto del Gamo, en el obispado de Coria, 1488 (ultraje a un crucifijo) o Valencia, finales del siglo XV (intento de crucifixión de otro niño) ${ }^{28}$.

Entre los más conocidos están, sin duda, los casos del niño de Sepúlveda (1468) o del Santo Niño de la Guardia $(1480)^{29}$. Este libelo contra los judíos fue uno de los más difundidos y, sin duda, tuvo consecuencias funestas. Por el supuesto crimen del niño de La Guardia fueron acusados varios judíos y conversos que, finalmente, acabaron en la hoguera el 16 de noviembre de 1491, en Ávila ${ }^{30}$. Es preciso indicar que, entre las posibles causas para abrir

${ }^{28}$ CARRETE PARRONDO, Carlos. «Descendientes del martirio del Niño de la Guardia». Helmantica, 1977, 28 , pp. 51-61, la cita está tomada de la p. 52.

${ }^{29}$ Consúltense, entre otros, CARRETE PARRONDO, Carlos. El judaísmo español y la Inquisición. Madrid: MAPFRE, 1992, pp. 77-83; MONER Michel. «Une légende en procès: le cas du Saint Enfant de La Guardia». En Etienvre, Jean Pierre (coord.). La légende: antropologie, histoire, littérature. Madrid: Casa de Velázquez y Universidad Complutense, 1989, pp. 253-266; ANTORANZ ONRUBIA, M ${ }^{\mathrm{a}}$. Antonia. «Noticias y tradiciones en torno al 'crimen ritual' de Sepúlveda». Sefarad, 2007, 67, pp. 469-475; SINGERMAN, Robert. Spanish and Portuguese Jewry: A Classified Bibliography. Wesport: Greenwood, 1993, pp. 197-199.

${ }^{30}$ Véase el clásico estudio de BAER, Yitzhak. Historia de los judíos en la España cristiana. Barcelona: Riopiedras, 1998; especialmente las pp. 829-849. Pueden consultarse los documentos relativos al proceso en FITA, Fidel. «La verdad sobre el martirio del Santo Niño de la Guardia, ó sea el proceso y quema (16 Noviembre 1491) del judío Jucé Franco en Ávila». Boletín de la Real Academia de la Historia, 1887, Tomo 11, en la siguiente dirección en línea:

$<$ http://www.cervantesvirtual.com/servlet/SirveObras/01360621092570728787891/ p0000002.htm\#I_5_> [consultada el 12 de marzo de 2009]. CARRETE PARRONDO señalaba: «No es necesario insistir en la falsedad de la acusación, tan generalizada como extravagante, según la cual en el proceso de La Guardia existió crimen ritual. La lectura de los documentos publicados por el P. F. Fita demuestran, por sí mismos, que el teórico suceso no reunió las características imprescindibles para poder ser considerado como tal crimen», entre otros aspectos, porque «jamás se encontraron los restos, supuestamente enterrados, del imaginario 'Niño de la Guardia'». «Descendientes del martirio», art. cit., pp. 53 y 55 . 
este proceso, está el hecho de que sólo unos meses después se publicaría el edicto de los Reyes Católicos, con lo que, de este modo, se creaba un clima antijudío propicio para decretar la expulsión ${ }^{31}$.

Además, sin duda, hubo numerosas obras a lo largo de la Edad Media y el Renacimiento que no hacían sino traer una y otra vez a la memoria casos como los anteriores. Si nos retrotraemos unos años antes de la expulsión hay que tener en cuenta que:

La guerra contra Granada comenzó en 1478, con la activa ayuda y participación de muchos judíos, que proporcionaron apoyo logístico, asistencia médica y consejeros para la corona castellana y sus tropas. A pesar de ofrecer tan indispensables servicios, la conquista gradual de las ciudades musulmanas iba acompañada del saqueo de los barrios judíos (por ejemplo, Málaga en 1485 y Gibralfaro en 1487). Mientras tanto, un violento panfleto anticonverso y antisemita, el llamado Libro de Alborayque, circulaba en Castilla y en Andalucía. En este libro el único nombre propio que aparecía era el de Diego Arias Sávila, converso, [...] personaje bien conocido de los lectores de la literatura castellana del siglo XV, ya que su nombre se encuentra en las Coplas de la Panadera, las Coplas del Provincial, en las obras de Gómez Manrique y en varios cancioneros. El año 1490 vio otro de los llamados «crímenes rituales judíos», el famoso niño de La Guardia, en que se acusó a varios judíos de crucificar a un niño cristiano el Viernes Santo ${ }^{32}$.

También en el siglo XVI, en la obra del converso Alonso de Espina, Fortalitium Fidei contra Iudeos Sarracenos aliosque christiane fidei inimicos, compuesta a mediados del siglo XV y que contó con varias ediciones también en la centuria posterior, se atribuía a los judíos una larga lista de crímenes rituales acaecidos en Ávila, Zamora, Segovia, etc. El tema debía interesar - y mucho- todavía a finales del siglo XVI, ya que en 1583 se publicó la obra de Rodrigo de Yepes, Historia de la muerte y glorioso martyrio del sancto Innocente, que llaman de la Guardia (Madrid: Juan Íñiguez de Lequerica), retomando así el suceso ocurrido en Toledo cien años antes. Recuérdese, ade-

${ }^{31}$ A finales del siglo XV se produjeron en España una serie de campañas «con las que se pretendía estigmatizar a los judíos como diabólicos activistas anticristianos. Tales campañas se alimentaron de un caudal creciente de acusaciones de profanaciones de hostias y asesinatos rituales que culminarían en 1491 en el caso de La Guardia [...] en el que sobre endebles pruebas se condenó a varios judíos toledanos por un pastiche de crímenes rituales, entre ellos el asesinato de un niño cuyo cadáver no apareció y que probablemente no existió jamás. El asunto de La Guardia fue un ejemplo egregio de proceso político, un caso amañado para remachar un alegato político en el momento álgido de las presiones de la Inquisición para lograr de los Reyes Católicos la expulsión de los judíos». GITLITZ, David M. Secreto y engaño. La religión de los criptojudíos. Salamanca: Junta de Castilla y León, 2002, p. 138.

${ }^{32}$ RODRÍGUEZ PUÉRTOLAS, Julio. «La poesía de la baja Edad Media». En I. M., Hassán; Izquierdo Benito, R. (coords.). Judíos en la literatura española, op. cit., pp. 87-109; concretamente la cita está tomada de las pp. 99-100. 
más, que en el siglo XVII compuso Lope de Vega su obra El niño inocente de La Guardia ${ }^{33}$.

Veamos ahora qué ocurría fuera de la Península Ibérica. Debemos retrotraernos dos siglos para encontrar que, a finales del siglo XIV, Geoffrey Chaucer estaba componiendo The Canterbury Tales siguiendo un método similar al que realizó Giovanni Boccaccio en su Decamerón. De este modo, la obra resulta un conjunto de relatos, cuentos o exempla que son contados por varios peregrinos que se dirigen a la catedral de Canterbury. En esta ocasión, nos interesa destacar aquí el conocido como «Cuento de la priora». Las concomitancias con la obra de González de Figueroa no pueden ser más evidentes:

The Canterbury Tales [...] includes one story based on a blood libel. The Prioress's Tale, which reflects contemporary prejudices, is the story of a widow's child murdered by Jews because he sings the hymn to the Virgin, «Alma redemptoris mater», when passing through the «Jewes Street» of some Asian city on his way to school. The Jews cut his throat and cast him into a pit, but he is miraculously enabled to continue singing, and in this way his body is discovered. The sequel is that all the Jews of the city are tortured and then massacred ${ }^{34}$.

Es posible que Chaucer se inspirara en la obra de Thomas of Monmouth, The life and miracles of St. William of Norwich de 1173. Este libro recoge la tradición de la primera acusación de crimen ritual aparecida en Europa. Se cuenta allí la historia de un niño cristiano, William de Norwich, quien apareció muerto el Sábado Santo de 1144. Los judíos de la localidad serán culpados de su muerte, produciéndose así la primera acusación de crimen ritual documentada en Europa.

Volviendo al relato incorporado en Los cuentos de Canterbury, se trata también de una obra escrita en verso, de carácter milagroso y antijudío ${ }^{35}$. Sabemos que los cuentos que recoge Chaucer tuvieron una amplia difusión por toda Europa; no obstante, la primera traducción española conservada de esta obra data del siglo XX. Fue Manuel Pérez y del Río-Cosa el primero que tra-

${ }^{33}$ Las publicaciones en torno al Santo Niño de la Guardia han llegado hasta el siglo XX y en ellas se sigue dando pábulo a la historia. Señala GITLITZ, David M. que «del drama que Lope de Vega escribió en el siglo XVII sobre el asunto [...] se hizo una edición en la Alemania de Hitler», op. cit., p. 138, nota 3. En España encontramos, por ejemplo, la obra de GUZMÁN, Antonio de. Historia del inocente trinitario el Santo niño de la Guardia. MARTÍNEZ MORENO, Martín. Historia del martirio del Santo Niño de la Guardia, ambas del siglo XVIII. Todavía en 1955 la editorial El Perpetuo Socorro publicaba la historia escrita por el redentorista SARABIA, Ramón. El Santo Niño de La Guardia. Narracción histórica de la vida, pasión y muerte del santo niño Juan (Cristóbal) Pasamontes.

${ }^{34}$ Encyclopaedia Judaica, op. cit., s. v. Chaucer, Geoffrey.

${ }^{35}$ DELANY, Sheila. «La priora de Chaucer, los judíos y los musulmanes». Indaga. Revista Internacional de Ciencias Sociales y Humanas, 2006, 4 pp. 223-242; para este aspecto consúltense, especialmente, las pp. 229-230. Véase también DEEN SCHILDGEN, Brenda. Pagans, Tartars, Moslems and Jews in Chaucer's Canterbury Tales. Gainesville: University Press of Florida, 2001. 
dujo al español la obra de Chaucer, en 1921, con un estudio inicial bastante riguroso en el que intentaba rastrear la fuente de cada uno de los cuentos que integran The Canterbury Tales. Sin embargo, no acierta exactamente con el origen del «Cuento de la Priora», pues según él «cualquier señalamiento sería muy arriesgado y por demás fantástico» y llega a suponer una posible influencia de la leyenda de Santo Dominguito del Val en la redacción de Chaucer $^{36}$. No obstante, no creemos que fuera necesario que éste se inspirara en los libelos españoles - aunque sabemos que viajó por España-, ya que en su mismo país habían circulado desde hacía siglos casos semejantes. Otros estudios más recientes en torno a los Cuentos de Canterbury tampoco explican el origen de este cuento y no reparan en la importancia de los libelos contra los judíos, así por ejemplo, Pedro Guardia Massó indica que nos encontramos ante «la historia de un milagro de Nuestra Señora, dentro de la recia corriente mariana del Medievo», fijando su atención, de este modo, en un único aspecto de la narración, pero sin contextualizar el texto por completo ${ }^{37}$. Tampoco nos explican mucho más Jesús Serrano y Antonio León en su estudio de la obra, ya que señalan que «el origen de lo que la Priora narra se pierde en lo nebuloso y sórdido de cualquier leyenda que pretende justificar de forma injustificable la violencia». Además, incluyen la narración dentro del «género devocional, de vida de santos y relatos milagrosos» ${ }^{38}$. Parece que casi todos los estudios en torno a la obra de Chaucer clasifican este cuento dentro de los relatos milagrosos y olvidan un aspecto muy significativo y presente en la mentalidad europea de la Edad Media y los Siglos de Oro como son los libelos de sangre contra los judíos y más concretamente la calumnia de crimen ritual que estamos viendo aquí.

Sin duda, nuestro ciego coplero debía conocer esta tradición, ya que encontramos exactamente los mismos motivos y elementos: el martirio del hijo de una viuda que canta el alma redemptoris mater, con el que solivianta el ánimo de un judío y será éste quien termine asesinándolo; no obstante, gracias a su canto podrá ser rescatado y morirá una vez que todos hayan presenciado el milagro. Quizá, la obra de Chaucer fuese traducida al español, aunque en la actualidad no conozcamos la existencia de ningún documento que así lo acredite, ya que, como se ha señalado: «las relaciones políticas entre España e Inglaterra, en la segunda mitad del siglo XIV, fueron suficientemen-

${ }^{36}$ Véase la cita y el comentario de este cuento en CHAUCER, Godofredo. Los Cuentos de Cantorbery. Pérez y del Río-Cosa, Manuel (ed.); Bonilla y San Martín, Adolfo (pról.). Madrid: Reus, 1921, pp. 78-80.

37 CHAUCER, Geoffrey. Cuentos de Canterbury, edición de Pedro Guardia Massó, Madrid: Cátedra, 2001, p. 40.

${ }^{38}$ Ambas citas en CHAUCER, Geoffrey. Cuentos de Canterbury. Serrano Reyes, Jesús L. (ed.); León Sendra, Antonio R. Madrid: Gredos, 2004, pp. 44 y 394, nota 248, respectivamente. 
te intensas para dar lugar a alguna comunicación literaria ${ }^{39}$. Ni que decir tiene que lo mismo pudo suceder con Portugal, es decir, los Cuentos de Canterbury pudieron conocerse en el país luso ya en el siglo XV, pues nos consta que una obra de un amigo de Geoffrey Chaucer, la Confessio Amantis de John Gower fue traducida primero al portugués y después al castellano. Es posible entonces que a nuestro coplero le llegase de forma oral o escrita una versión de este «Cuento de la Priora», desde una fuente española o portuguesa, pues no olvidemos, además, que este pliego suelto salió de las prensas lisboetas. Sin embargo, volveremos de nuevo sobre este asunto.

Es probable, por tanto, que, a finales del siglo XVI, el relato de Chaucer fuese más conocido de lo que suponemos y, de este modo, cada autor rehacía una misma versión, de ahí que en todas ellas encontremos un conjunto amplio de similitudes, aunque siempre incorporando también alguna variante, de acuerdo con los intereses concretos que cada uno persiguiese. Así, por ejemplo, es evidente que en el caso del «Cuento de la priora» de Chaucer el judío acabe ajusticiado, ya que, aunque tenga como punto de partida el caso de William de Norwich (1144), al final del relato la priora alude claramente al niño Hugh de Lincoln, otro libelo de sangre contra los judíos que se difundió a partir de 1255:

His body was found in a well in the Jewish quarter of Lincoln by his mother, about Passover time 1255, near the house of a Jew named Copin. Under torture, Copin stated that he had killed the child for the fulfillment of the Jewish paschal rites. Henry III went to Lincoln to take charge of the proceedings. Copin was barbarously executed and some 90 Jews [...]. Eighteen of them were put to death and the others pardoned through the influence of the king's brother, Richard of Cornwall ${ }^{40}$.

Así pues, Geoffrey Chaucer al hacerse eco de este acontecimiento en el que, finalmente, varios judíos fueron apresados, torturados y masacrados, no podía acabar su relato de otro modo. La leyenda recogida en nuestro pliego probablemente alcanzó también difusión oral a través de la predicación, ya que, tanto franciscanos como dominicos tuvieron un papel muy activo en este sentido, especialmente durante la Edad Media, al promover la conversión de los que consideraban herejes, aumentando en muchas ocasiones, las tensiones y el clima de marginación hacia los judíos ${ }^{41}$.

No debemos olvidar tampoco que no es infrecuente encontrar algunas relaciones de sucesos en pliegos sueltos poéticos que narran un milagro y la

${ }^{39}$ CHAUCER, Godofredo, op. cit., p. 11.

${ }^{40}$ Encyclopaedia Judaica, op. cit., s. v. Hugh of Lincoln. Se incluye al final de la entrada bibliografía sobre el asunto.

${ }^{41}$ Véanse, por poner un ejemplo, los sermones sexto y vigésimo cuarto que se recogen en CÁTEDRA, Pedro M. Sermón, sociedad y literatura en la Edad Media. San Vicente Ferrer en Castilla (1411-1412). Salamanca: Junta de Castilla y León, 1994, pp. 323-335 y 535-545. 
posterior conversión de judíos, luteranos, etc. Debemos tener en cuenta también que estas conversiones se basan en diferentes motivos folklóricos, algunas se encuentran ya en la Biblia — muy conocida es la de san Pablo_- pero también registradas en el Motif-Index de Thompson ${ }^{42}$. Por el final de la narración se deduce que se valoraba la conversión de los judíos al cristianismo, especialmente a través de un caso como éste en el que la misma se produce gracias a que el judío presencia el milagro y no duda en bautizarse. No es, por tanto, una conversión forzada - como tan a menudo había ocurrido en la historia reciente de los judíos-, sino elegida voluntariamente y con pleno convencimiento.

Si Francisco González de Figueroa siguió una versión similar al relato de Chaucer, ¿por qué no incorporó en su relación la tortura y muerte del judío?, ¿qué perseguía el ciego coplero al convertir al catolicismo al judío de su narración? Debemos tener en cuenta que uno de los géneros que mayor éxito gozó a partir de la segunda mitad del siglo XVI fueron los «casos horribles y espantosos», esto es, relaciones de sucesos en las que los elementos truculentos y tremendistas se dan cita a lo largo de estas obras y, a su vez, vertebran dichas composiciones. Como ocurre en otros casos de esta literatura poética de cordel, el coplero podía haber aunado el milagro con la relación tremendista y, de este modo, junto a la intervención de la Virgen para que el niño siga cantando incluso enterrado, Francisco González de Figueroa podía haber incluido un remate tremendista en el que el judío fuese ajusticiado por su crimen. Así, por ejemplo, la unión de un hecho milagroso y el final truculento se dan cita en obras como la de Francisco Casado que lleva por título: Obra nuevamente sucedida en el castillo de Salças en el Reyno de Cataluña, la qual trata de un maravilloso milagro que obró Nuestra Señora del Carmen. Trata de cómo una mesonera dio la muerte a su marido y a quatro hijos suyos por irse con un hariero [...] y por ciertas visiones que vido se vino a presentar a la iusticia y cómo fue sentenciada a ahorcar y estuvo colgada desde las tres de la tarde hasta otro día a las nueue sin morir y mirándola la iusticia le hallaron el escapulario, y quitándoselo murió; o bien otra composición de Diego Gasque ${ }^{43}$ : Caso espantoso suscedido en el Reyno de Nauarra en la ciudad de Panplona a una mujer, la qual decía que la mujer que paria dos criaturas que era la una del marido y la otra de su amigo, y cómo por voluntad

${ }^{42}$ Para todos estos aspectos, véase CARRO CARBAJAL, Eva Belén; SÁNCHEZ PÉREZ, María, op. cit., especialmente pp. 21-35.

${ }^{43}$ Existen numerosos elementos tradicionales y folklóricos que se dan cita en esta obra. Véase el estudio de CARRO CARBAJAL, Eva Belén. «Elementos folklóricos de las noticias en verso difundidas en pliegos sueltos durante el último tercio del siglo XVI». En López Poza, Sagrario (ed.). Las noticias en los siglos de la imprenta manual. Homenaje a Mercedes Agulló, Henry Ettinghausen, $M^{a}$. Cruz García de Enterría, Giuseppina Ledda, Augustin Redondo y José Simón. La Coruña: SIELAE \& Sociedad de Cultura Valle Inclán, 2006, pp. 31-36. 
de Dios vino a parir siete criaturas juntamente, con las grandes traiciones que hizo y un milagro que la Virgen de los Remedios obró ${ }^{44}$.

Sin embargo, parece claro que Francisco González de Figueroa no pensaba componer esta vez un «caso horrible y espantoso» a pesar de que, entre la nómina de sus obras, figure una relación de sucesos tremendista ${ }^{45}$. Lo cierto es que no parece muy viable que, si este coplero estuviese narrando un suceso acontecido realmente, la justicia no interviniera para castigar al asesino. Aunque en siglos posteriores sí encontraremos un mayor número de casos en los que los diferentes crímenes que se relatan en estas obras queden impunes, en los pliegos sueltos poéticos del Quinientos lo habitual es que o bien la justicia civil o bien la celestial acaben por imponer su castigo sobre los culpables. En el caso que ahora nos ocupa, el desenlace de la narración resulta aún más anómalo al existir un componente religioso de gran carga sobre la obra. Examinando las narraciones que conservamos del Quinientos no resulta creíble que el judío se pudiese eximir de la culpa simplemente con su conversión al catolicismo y con la entrega de una parte de sus bienes — ni siquiera todos- para la viuda. Es significativo, por tanto, que no se abriera un procedimiento judicial, ni que en la narración se nos hable de algo similar, lo que indica que el coplero no buscaba un fin vindicativo, sino más bien conciliador y abierto, intentando demostrar que, antes o después, triunfaría la fe católica y que los enemigos de dicha confesión —en este caso judíos, pero entiéndase también musulmanes, o luteranos si atendemos a otra de las composiciones que integran el pliego - tendrían que abrazar el catolicismo. La narración podría resultar verosímil para la sociedad de los Siglos de Oro, pero resulta obvio que nos hallamos ante una composición basada en elementos folklóricos y legendarios.

Es evidente también que, por aquellos años —recordemos que la licencia de los inquisidores que principia el pliego está fechada en 1578_, la sociedad renacentista estaba sensibilizada contra los judíos, ya que el Santo Oficio continuaba teniendo una intensa actividad en la búsqueda de luteranos, herejes, criptojudíos, etc. ${ }^{46}$. Si bien es cierto que la mayor parte de los procesos

${ }^{44}$ Se trata de las entradas 106 y 216 del Nuevo Diccionario.

${ }^{45} \mathrm{Se}$ trata de la Obra nueva y muy berdadera donde se trata el doloroso sucesso que sucedió en la villa de sant Clemente, en el mes de henero del año de 1586, de la dolorosa muerte que dio una muger a su marido por casarse con su amigo y fue en su ayuda una tia suya y su amigo, y de la justicia que dellos se hizo. Hubo, al menos, dos ediciones de esta obra, ambas salidas de las prensas del Molino de la Rovella, en Valencia, en 1587. Véanse las entradas 230 y 231 del Nuevo Diccionario. Para un acercamiento a este pliego, puede consultarse SÁNCHEZ PÉREZ, María. «La retórica de las relaciones tremendistas del siglo XVI». En San José Lera, Javier (ed. y coord.). Praestans labore Victor. Homenaje al profesor Víctor García de la Concha. Salamanca: Universidad de Salamanca, 2005, pp. 217-234.

${ }^{46}$ La bibliografía en torno a este asunto es abundante, pero destacamos ahora, como estudio panorámico en relación con el tema que nos ocupa, CARRETE PARRONDO, Carlos. El judaísmo español, op. cit. 
abiertos contra judaizantes tuvieron lugar en la primera mitad del siglo XVI, éstos continuaron en la segunda parte de la centuria - e incluso hasta bien avanzado el siglo XVIII-, aunque el número de ellos fue decreciendo paulatinamente $^{47}$. No obstante, como ha señalado Antonio Domínguez Ortiz:

Parece evidente que los reyes de España nunca sintieron el problema converso de la forma primaria y elemental que se advierte en la mayoría de los españoles de su tiempo. Desconfiaban de ellos como grupo, pero apreciaban las cualidades de muchos y se sirvieron de ellos sin los remilgos ridículos cada vez más extendidos. Lo hizo Fernando el Católico, y también Felipe II sabía hacer excepciones a la ley de la limpieza ${ }^{48}$.

Pensemos que, precisamente en los últimos decenios del siglo XVI, la Inquisición portuguesa se encontraba en un período culminante en su persecución de judaizantes. No debemos olvidar tampoco que, en principio, la Inquisición no se estableció para atacar directamente a los judíos, sino para velar por la doctrina católica y perseguir la herejía ${ }^{49}$. En este sentido se represaliaba a todos aquellos que bajo la apariencia de nuevos cristianos seguían manteniendo sus prácticas en secreto. Incluso se persiguió a aquéllos que, aun sintiéndose católicos sinceros, seguían manteniendo alguna costumbre que se consideraba judía. Ahora bien, como afirmaba Jaime Contreras:

La Inquisición buscaba al hereje dando palos de ciego. No parecía importar demasiado, porque, siguiendo las exigencias de los estereotipos, aquella herejía sólo podía nacer entre los hijos y nietos de judíos. Inclinados hacia el pecado de los padres, los hijos se sentían compulsivamente inclinados a judaizar. Éste era el espíritu que animaba a los perseguidores. De hecho, les fue difícil reconocer que, a veces, ocurría todo lo contrario: la ascendencia familiar notada de converso servía para vivir un cristianismo más intenso, ortodoxo, místico, casi dogmático ${ }^{50}$.

Es bien conocida, por tanto, la dura represión que llevo a cabo la Inquisición contra los judaizantes. Sin duda, son elevadas las cifras de procesados

\footnotetext{
${ }^{47}$ Por ejemplo, en Granada, en 1592, se encontró un grupo de judaizantes que fueron condenados a diversas penas. Consúltese, para esta ciudad, GARCÍA FUENTES, José María. La Inquisición en Granada en el siglo XVI. Granada: [el autor], 1981. Véase, de nuevo, el estudio fundamental de D. M. GITLITZ, op. cit. Consúltese también ALPERT, Michael. Criptojudaísmo e Inquisición en los siglos XVII y XVIII. Barcelona: Ariel, 2001.

${ }^{48}$ DOMÍNGUEZ ORTIZ, Antonio. Los judeoconversos en la España Moderna. Madrid: MAPFRE, 1992, p. 60. En efecto, parece que el sentimiento antijudío estaba mucho más extendido entre la población que entre los monarcas de la Casa de Austria.

${ }^{49}$ Como sentenciaba DOMÍNGUEZ ORTIZ, Antonio. «La Inquisición contra los falsos conversos; la expulsión contra los judíos». En su obra Los judeoconversos en España y América. Madrid: Istmo, 1978, p. 29.

${ }^{50}$ CONTRERAS, Jaime. «Conversos y judaizantes después de 1492: una relación desigual». En Méchoulan, Henry. Los judíos de España, op. cit., pp. 60-70; cita tomada de la p. 63 .
} 
que acabaron en la hoguera ${ }^{51}$ y muchas las comunidades que desaparecieron en la Península. Pensemos que la instauración del Santo Oficio en Portugal fue más tardía que en Castilla y que se creó específicamente «a causa de la

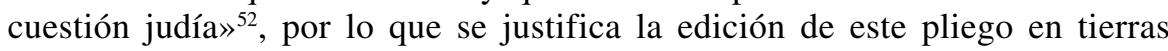
lusas. Además, por lo que respecta a Portugal, los conversos tenían prohibido abandonar el país, por lo que muchos de ellos deseaban poder emigrar, no sólo por el miedo a la acción inquisitorial, sino por motivos relacionados con el comercio y la economía ${ }^{53}$.

Además, como apuntábamos más arriba, debemos tener en cuenta también que, aunque en menor medida que en años anteriores, todavía a mediados del Quinientos, en España, seguían descubriéndose nuevos focos y comunidades de judaizantes ${ }^{54}$, especialmente porque, por aquellas décadas, se intensificó el problema sobre los Estatutos de la limpieza de sangre ${ }^{55}$. Hay que destacar también el hecho de que este ciego coplero fuera «vezino de Murcia», pues sabemos que un importante foco de judaizantes fue descubierto allí a mediados del siglo XVI:

${ }^{51}$ La hoguera fue el método utilizado — principalmente por el Santo Oficio- para ajusticiar a los herejes, los homosexuales y los acusados de bestialismo. La horca, por su parte, fue empleada fundamentalmente para castigar los delitos que atendía la justicia civil. Vid. RODRIGUEZ SÁNCHEZ, Ángel. «La soga y el fuego. La pena de muerte en la España de los siglos XVI y XVII». Cuadernos de Historia Moderna, 1994, 15, pp. 13-39.

${ }^{52}$ NOVINSKY, Anita, art. cit., p. 101.

53 «Tales proyectos causaban en Portugal viva irritación, y no hay que ser muy suspicaz para pensar que la causa no era sólo el celo por la pureza de fe. La salida de los marranos suponía la pérdida de la minoría más activa, la única que, por su presencia en todas las plazas comerciales, mantenía la riqueza de la nación. Pero a la vez se la quería tener humillada y expoliada». En DOMÍNGUEZ ORTIZ, Antonio. Los judeoconversos en España y América, op. cit., p. 61.

${ }^{54}$ Se ha apuntado que: «Durante los primeros años de esta centuria [siglo XVI] la virulencia inquisitorial ha amainado, no tanto porque se ha aplacado el fuego anticonverso como porque los principales núcleos han sido ya exterminados, pero el rescoldo permanece y cuando menos se espera aparecen, aquí y allá, focos judaizantes de diversa importancia». No obstante, se señala más adelante que «aunque no sabemos con certeza las cifras de procesados por la Inquisición desde el momento de su establecimiento, no debe de andar muy descaminado el número que proporciona el Memorial de Defensa del Estatuto de Limpieza de Sangre de la Catedral de Toledo cuando afirma que hasta entonces (1547) se habían reconciliado, penitenciado y quemado en España más de 50.000 judaizantes». En BLÁZQUEZ DE MIGUEL, Juan. Inquisición y criptojudaísmo. Madrid: Kaydeda, 1988, pp. 129-130 y 149.

${ }^{55}$ Como sabemos, los Estatutos de limpieza de sangre fueron unas reglamentaciones que estaban destinadas a limitar o excluir a los conversos de cualquier congregación civil o religiosa. Comenzaron en el siglo XV, pero durante los Siglos de Oro, cuando la preocupación por la limpieza de sangre llegó a convertirse en una verdadera obsesión, los Estatutos empezaron a florecer por cualquier parte. Véanse, entre otros, SICROFF, Albert A. Los estatutos de limpieza de sangre. Controversias entre los siglos XV y XVII. Madrid: Taurus, 1985; HERNÁNDEZ FRANCO, Juan. Cultura y limpieza de sangre en la España moderna: Puritate sanguinis. Murcia: Universidad, 1996. 
$\mathrm{Y}$ es en estos momentos de tranquilidad inquisitorial antijudía cuando se descubre un importante foco en una ciudad que hasta entonces había pasado casi desapercibida en relación con este problema y cuyo Tribunal estaba considerado como poco conflictivo: Murcia. En efecto, en 1556 es detenido un grupo de judaizantes dirigido por el franciscano fray Luis de Valdecañas, integrado por personas de toda condición social, abarcando desde caudalosos comerciantes [...], hasta esclavos [...], pasando por boticarios, un médico, el doctor Ulloa, un notario del obispo [...] , y un miembro de la nobiliaria familia de los Fajardo. Los procesos duraron largos años, terminando en 1563 con la relajación del fraile y del esclavo ${ }^{56}$.

Sin duda, la comarca debió conmocionarse ante un hecho de estas características y es muy probable que Francisco González de Figueroa conociera este suceso acontecido veinte años antes que la impresión de su obra. No debemos descartar, por tanto, que este coplero decida decantarse por esta narración de tono antijudío, al haber podido conocer de primera mano este proceso contra judaizantes. No conservamos ninguna edición impresa en España, pero - como ya señalábamos anteriormente- es probable que la obra salida de las prensas lisboetas sea reedición de una obra española. La población de la Península estaba sensibilizada contra los judíos, ya que, precisamente el «problema judío» seguía afectando a la vida cotidiana de la sociedad renacentista muchos años después de la expulsión y, por lo tanto, la Inquisición siguió persiguiendo a los nuevos cristianos.

Ahora bien, nos importa ahora resaltar el porqué de ese final: la conversión del judío. Lo habitual, como ocurre en este tipo de leyendas, hubiera sido que el judío fuera castigado y, especialmente, con la pena más alta, la hoguera. No resulta lógico tampoco que ni siquiera se le confiscaran todos sus bienes - de acuerdo con las pautas que se seguían cada vez que se le abría un proceso a cualquier judaizante-, pues se nos dice que él mismo decide entregar un dinero para la viuda. Final, por lo tanto, totalmente insólito, ya que no hay castigo, el infanticidio queda impune y únicamente se destaca la conversión voluntaria y la alabanza a la Virgen. Este aspecto nos hace sospechar que la decisión de perdonar al judío no es un elemento introducido voluntariamente por el autor de la composición. Recordemos que el pliego lleva licencia de impresión del Santo Oficio, lo cual puede ser indicio de que el tema era delicado y espinoso, y Francisco González de Figueroa consideraba, quizá, que no era oportuno difundir esta obra sin esa precaución ${ }^{57}$. De este modo, es probable que la leyenda fuese conocida en la época y que dicho final estuviese ya en la fuente que el autor utilizó.

${ }^{56}$ BLÁZQUEZ DE MIGUEL, Juan, op. cit., p. 153.

${ }^{57}$ Sobre el control ejercido por Santo Oficio, véanse los comentarios expuestos sobre estos aspectos relativos a los pliegos sueltos poéticos en CÁTEDRA, Pedro M. Invención, difusión y recepción de la literatura popular impresa (siglo XVI). Mérida: Editora Regional de Extremadura, 2002, pp. 171-197; CARRO CARBAJAL, Eva Belén; SÁNCHEZ PÉREZ, María, op. cit., especialmente pp. 35-50. 
Teniendo en cuenta todos los aspectos expuestos anteriormente, debemos empezar a extraer algunas conclusiones. Es sumamente significativo el hecho de que tanto el contexto geográfico como el temporal resulten, cuanto menos, de origen medieval. Es importante destacar que nos hallamos ante un personaje judío, no un converso judaizante. Si el autor hubiese tenido como referente la realidad hispano-portuguesa de la época, es probable que algunos elementos de la composición hubieran diferido bastante de los que aquí se nos presentan: lo lógico hubiese sido partir de un personaje que fuese un cristiano nuevo, judaizante en este caso, y que, siguiendo los pasos normales de cualquier proceso inquisitorial de la época, en primer lugar el Santo Oficio le habría confiscado todos sus bienes - so pretexto de pagar los gastos del proceso y de su estancia en la cárcel-y, después, al demostrarse la culpabilidad en el asesinato, el converso hubiera sido castigado con la habitual pena de «relajación al brazo secular» ${ }^{58}$, es decir, a la muerte en la hoguera. Sin embargo, como hemos visto, nada de esto ocurre.

El contexto medieval parece imponerse, por tanto, al observar cómo nos hallamos ante un personaje judío, que vive en barrio distinto al del resto de la ciudad, lo que nos hace pensar en una posible judería cerrada o cerrable y que, precisamente, lo que hastía al judío es que ese niño pase delante de su casa - alabando con cánticos a la Virgen-, por su propio barrio, «do fue nascido y criado» (v. 80). Este dato puede apuntar a dos aspectos: por una parte - como se señala en la obra-, a la necesidad de poder apresar al niño y «cogello en despoblado» (v. 62), sin ser visto por nadie; aunque, lo más lógico y probable es que esté remitiendo a una situación medieval, a la que tenían precisamente los judíos cuando vivían en la Península antes de su expulsión, aludiendo así a una judería o guetto en la ciudad que, por supuesto, a finales del siglo XVI habían desaparecido por completo ${ }^{59}$.

Es probable también que, si Francisco González de Figueroa hubiese decidido tomar como referente la situación socio-cultural de la Península en la época, posiblemente se hubiese decantado por narrar una historia como la del Santo Niño de la Guardia, ocurrida a finales del siglo XV y, por tanto, mucho más cercana en el tiempo, donde sus protagonistas fueron, fundamentalmente, cristianos nuevos, acusados de judaizar, en un primer momento, y de haber realizado un crimen ritual, posteriormente.

${ }^{58}$ Esta formulación tan eufemística responde al hecho de que, teóricamente, el Tribunal de la Inquisición no condenaba a nadie a muerte. Por lo tanto, con la expresión «relajación al brazo secular» se entiende que el Santo Oficio entregaba al reo a la justicia civil para que ésta se encargara de su castigo. Consúltese FERNÁNDEZ GIMÉNEZ, María del Camino. La sentencia inquisitorial. Madrid: Editorial Complutense, 2000.

${ }^{59}$ Con la expulsión de los judíos de Castilla y Aragón, los conversos que, al final, optaron por quedarse en la Península debieron abandonar precisamente esos barrios judíos al pasar a ser cristianos nuevos. Es más, los propios judíos decidieron dispersarse e incluso abandonar sus ciudades y trasladarse a otros lugares para no levantar sospechas y poder pasar desapercibidos más fácilmente en el nuevo asentamiento. 
Resulta también llamativo que el coplero se distancie deliberadamente de la realidad de su entorno al elegir la ciudad de Aviñón como lugar donde se producen los hechos. Recordemos que los judíos habían sido expulsados de Francia en el siglo XIV, por lo tanto, tendríamos que remontarnos, de nuevo, a la época medieval para poder encontrarlos asentados en dicho país.

Por otra parte, si bien los sucesos aquí narrados acaecen en Francia, la segunda relación milagrosa que aparecía en el pliego se situaba en «Alemaña, la Alta», ¿nos están indicando estos aspectos que la fuente que utilizó Francisco González de Figueroa pueda ser de origen francés, alemán, o por qué no, flamenco? Pensemos que «the story [la calumnia de crimen ritual sobre Hugh de Lincoln] is reverently mentioned by Chaucer in The Prioress's Tale, and the alleged martyrdom was commemorated in many English and French ballads» ${ }^{60}$. Es importante señalar también que, desde 1568, la Casa de Austria mantenía una guerra con Flandes para intentar preservar sus dominios sobre aquellas tierras. No es improbable pensar, por tanto, que quizá la fuente utilizada por este coplero popular pudiera provenir de alguno de estos lugares. En aquellos momentos, la transacción de noticias debía de producirse con bastante frecuencia entre los correligionarios que estaban en la Península y los soldados que se encontraban en Flandes y que volvían con relativa asiduidad a Castilla. Con todo, es probable que existiera una fuente concreta, de origen medieval, y que nuestro coplero se basara en alguna que le llegara más tardíamente.

Lo que sí resulta evidente es que González de Figueroa reanuda una añeja tradición y que nos encontramos ante una leyenda antijudía de extensión paneuropea que tiene varias manifestaciones: las más antiguas documentadas son inglesas, con William de Norwich en 1144 y Hugh de Lincoln en 1255. Posteriormente, en España, se situaría la de Santo Dominguito del Val, en el siglo XIII. Retoma de nuevo la leyenda Geoffrey Chaucer en el siglo XIV en su «Cuento de la priora»y, probablemente, a través de todos estos testimonios, esta calumnia de crimen ritual contra los judíos se extendería por media Europa, a través de textos escritos en distintas lenguas; pero también su difusión se produciría a través de la predicación y, cómo no, los impresos populares.

Fecha de recepción: 1 de abril de 2009

Fecha de aceptación: 3 de noviembre de 2009

${ }^{60}$ Encyclopaedia Judaica, op. cit., s.v. Hugh de Lincoln. 